\title{
Effects of Air-Dried Leaves of Evergreen Broad-Leaved Trees on Sound Absorption Property ${ }^{1}$
}

\author{
Su-Young $\mathrm{JUNG}^{2} \cdot$ Ree-Keun $\mathrm{KONG}^{3} \cdot$ Kwang-Soo $\mathrm{LEE}^{2} \cdot$ Hee-Seop BYEON(D, ${ }^{4, \dagger}$
}

\begin{abstract}
This research was conducted to analyze the sound absorption effect of air-dried leaves from two evergreen tree species found in Korea's warm-temperate and subtropical regions. As eco-friendly sound absorption materials, Dendropanax morbiferusa, and Fatsia japonica leaves were prepared in three specimen units sizes $0.5 \times 0.5 \mathrm{~cm}^{2}, 1.0 \times 1.0 \mathrm{~cm}^{2}$, and $2.0 \times 2.0 \mathrm{~cm}^{2}$, and each of them was formed at a thickness of $1.00 \mathrm{~cm}, 1.75 \mathrm{~cm}$, and $2.50 \mathrm{~cm}$. The measured sound absorption coefficients (SAC) for 18 conditions were comparatively analyzed in this study. The SAC of both tree species was significantly improved by increasing the dried leaf layer thickness. These results showed a more consistent and distinct trend for both tree species under the condition of $0.5 \mathrm{~cm}^{2}$ in dried leaf size compared to other leaf specimen sizes. However, as the thickness increased, the difference in sound absorption effect according to the leaf size tends to decrease overall. In the case of D. morbiferus, there was no significant difference in SAC based on leaf size under the condition of $2.5 \mathrm{~cm}$ thickness $(p<0.05)$. The highest mean SAC was found in a $2.5 \mathrm{~cm}$ thick condition with a leaf size of $0.5 \times 0.5 \mathrm{~cm}^{2}, 0.549$ for D. morbiferusa, and 0.594 for $F$. japonica, respectively.
\end{abstract}

Keywords: sound absorption, evergreen broad-leaved tree, impedance measurement tube, thickness, air-dried leaf

\section{INTRODUCTION}

The distribution area of evergreen broad-leaved forest in Korea is estimated to be about 10,000 ha, and their distribution area is gradually expanding along with global warming (Korea Forest Service, 2002; National Institute of Forest Science, 2014). Forests are the largest carbon pool on earth (Vashum and
Jayakumar, 2012) and the constituent tree species of warm-temperate and subtropical forest zones have a high potential to play a major role in adapting to climate change and mitigating global warming (Korea Forest Service, 2018). In this regard, evergreen broadleaved forests and trees in the southern region of Korea are also playing a role in absorbing carbon from nature, and the value of resource utilization as an

${ }^{1}$ Date Received July 21, 2021, Date Accepted August 5, 2021

2 Warm-Temperate and Subtropical Forest Research Center, National Institute of Forest Science, 22 Donnaeko-ro, Seogwipo-si, Jeju-do, 63582, Republic of Korea

${ }^{3}$ College of Agriculture \& Life Science, Gyeongsang National University, 501 Jinjudae-ro, Jinju-si, Gyeongsangnam-do, 52828, Republic of Korea

${ }^{4}$ College of Agriculture \& Life Science, IALS, Gyeongsang National University, 501 Jinjudae-ro, Jinju-si, Gyeongsangnam-do, 52828, Republic of Korea

$\dagger$ Corresponding author: Hee-Seop BYEON (e-mail: hsbyeon@gnu.ac.kr, ORCID: 0000-0001-7952-9991) 
eco-friendly material is also gradually increasing.

Recently, in addition to sustainable environmental conservation and maintenance, demands for improvement of living environments such as industrial sites and residential spaces are also increasing, and the field of noise reduction in living environments is no exception (Ersoy and Küçük, 2009; Bujoreanu et al., 2017; Koizumi et al., 2002). Industrial sound absorption generally uses synthetic fibers, sponge, glass or rock wool, foam, fabric, etc. However, these industrial sound-absorbing materials may directly or indirectly cause environmental pollution when discarded, and also have disadvantages that are difficult to reuse and incinerate. Various studies have been conducted on the relationship between noise and wood source materials and/or treatment; wood substrates (Kang and Park, 2001), wood structure and gravity, carbon and heat treatment (Byeon et al., 2010; Won et al., 2015; Kang et al., 2019c), wood by delignification treatment (Kang and Lee, 2005.), resonator by hole position (Hwang et al, 2008), wood bark particle mats (Kang et al., 2019b), composite particle board (Iswanto et al., 2020; Kang et al., 2015), the oak mushroom bed log (Kang et al., 2008), coconut coir fibers (Nor et al., 2004), bamboo fiber (Koizumi et al., 2002), traditional Koreannatural wallpapers (Jang et al., 2018), undried leaves of evergreen broad-leaved trees (Jung et al., 2020), recycled materials (Lee, 2001) etc.

The purpose of this study is to compare and analyze the sound-absorbing effect of air-dried leaves in order to verify or expand their practicality as an eco-friendly sound-absorbing material of two evergreen broad-leaved tree species native to the southern region of Korea.

\section{MATERIALS and METHODS}

\subsection{Processing of sound absorbing materials}

In order to investigate the sound absorption coefficient (SAC) according to the specimen size and layer thickness of the air-dried leaves of evergreen broadleaf trees, the leaf of Korean dendropanax (Dendropanax morbiferus) and Japanese aralia (Fatsia japonica) were collected in National Institute of Forest Science. SAC is a parameter commonly used to observe the acoustic properties of sound absorbing materials that play an important role in noise attenuation (Kang et al., 2019a; 2019c). Two evergreen broad-leaved trees of $D$. morbiferus and $F$. japonica are mostly distributed in subtropical and warm temperate forest zone in Korea. Before this experiment, three samples for each tree species were collected and estimated using thickness measuring instrument (PDN-21, Peacock, Japan) and leaf area measuring instrument (Li-3000C, Licor). Using a measuring straw cutter, the specimen was cut into three unit sizes: $0.5 \times 0.5 \mathrm{~cm}^{2}, 1.0 \times$ $1.0 \mathrm{~cm}^{2}$, and $2.0 \times 2.0 \mathrm{~cm}^{2}$. As shown in Fig. 1, all the specimens as configurations of biomass materials (Oldham et al., 2011), were under a synthesized pressure $\left(0.0256 \mathrm{kgf} / \mathrm{cm}^{2}\right)$. The leaves of two evergreen

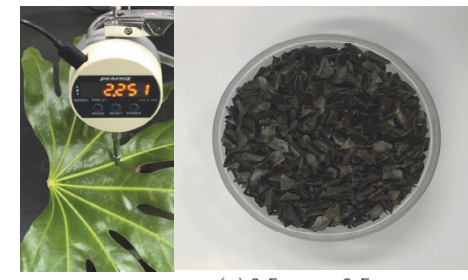

(a) $0.5 \mathrm{~cm} \times 0.5 \mathrm{~cm}$

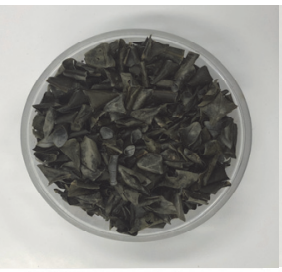

(b) $1.0 \mathrm{~cm} \times 1.0 \mathrm{~cm}$

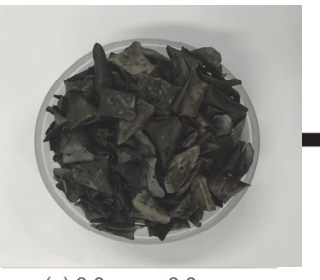

(c) $2.0 \mathrm{~cm} \times 2.0 \mathrm{~cm}$

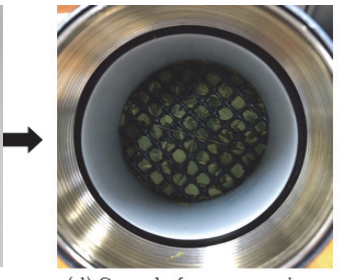
(d) Sample for measuring
sound absorption coefficent

Fig. 1. Preparation of specimen for measurement of sound absorption coefficient (SAC) for evergreen tree species. 
species were dried to an average moisture content of about $12 \%$ to $13 \%$ for 2 weeks in a constant temperature and humidity room, and the average moisture content of air-dried leaves was $13.09 \%$ for D. morbiferus and $12.50 \%$ for $F$. japonica (Table 1 ).

\subsection{Estimation of sound absorption coefficient}

The measurement principle of the impedance tube method is mainly divided into two types; a method using the standing wave ration and the transfer function method (Hakamada et al., 2006). In this study, the sound absorption characteristics of air-dried leaves were investigated by the latter transfer function method (Fig. 2). In detail, the absorption properties test apparatus for the two microphone method consisted of an impedance measurement tube used here (Type 4206A, B\&K, Denmark) in the right side of Fig. 2, a sign analyzer unit (Type 2035, B\&K, Denmark), a power amplifier (Type 2706, B\&K, Denmark) and two microphones (Type 2670, B\&K, Denmark), as shown in the left side of Fig. 2 (User manual, 2002). The range of the frequency measurement was $100 \mathrm{~Hz}$ $3,200 \mathrm{~Hz}$ in a middle type impedance measurement tube. The SAC was determined according to ASTM C 384-04 (2016).

Following calibration with a sponge, the absorption coefficient of the material was measured 100 times each specimen. Three replication tests were conducted on each specimen and the mean value of the test results was recorded. After the experimental measurement of SAC, an average SAC was calculated by dividing denominator into numerator in the frequency range of the measurement using the following equation(1) (Won et al., 2015; Jung et al., 2020).

$$
\text { Sound absorption coefficient }=\frac{\text { Total absorption value }}{\begin{array}{c}
\text { Total number of } \\
\text { measurement }
\end{array}}
$$

SACs are shown in Table 2, and the values were statistically analyzed performed by Duncan's multiple range test using PASW Statistics 18.0 (SPSS Inc., Chicago, IL, USA).

Table 1. Characteristics of the leaf by two evergreen broad-leaved tree species

\begin{tabular}{cccccc}
\hline \multirow{2}{*}{ Classification } & Leaf area & Length & Width & Thickness & $\begin{array}{c}\text { Moisture content of } \\
\text { air-dried leaves }\end{array}$ \\
\cline { 2 - 6 } & $\left(\mathrm{cm}^{2}\right)$ & $(\mathrm{cm})$ & $(\mathrm{cm})$ & $(\mathrm{mm})$ & $(\%)$ \\
\hline \hline D. morbiferus & 60.03 & 11.30 & 5.03 & 0.632 & 13.09 \\
\hline F. japonica & 1370.36 & 138.83 & 18.20 & 1.279 & 12.50 \\
\hline
\end{tabular}

Note: The data is the average of 3 samples measured. Leaf area, length, width and thickness were measured at green state. (Jung et al., 2020)
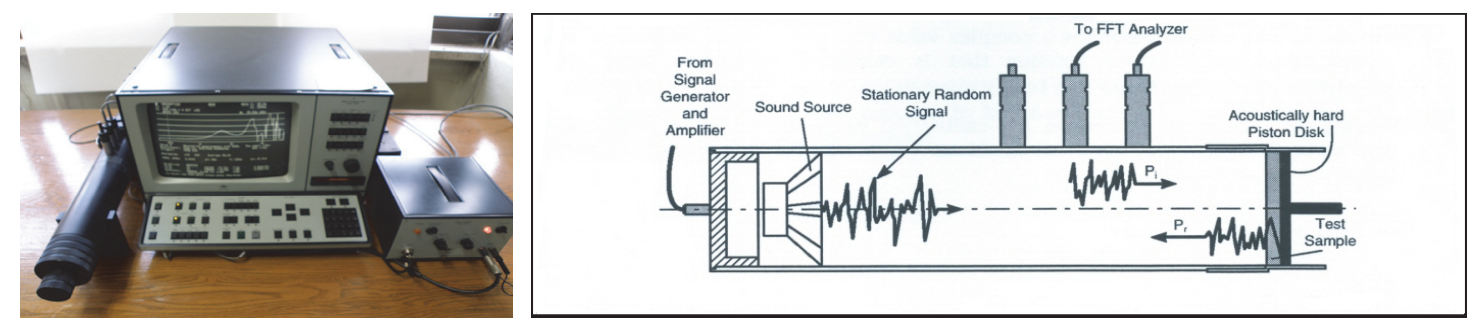

Fig. 2. Two-microphone impedance measurement tube (left side) and cut-away diagram of the impedance measurement tube (right side) (Jung et al., 2020). 


\section{RESULTS and DISCUSSION}

\subsection{Sound absorption coefficients by leaf thickness and specimen size}

The relationship between layer thickness and unit size of the air-dried leaf specimen and SAC is shown in Table 2. Leaf thicknesses and specimen sizes were differentiated with thicknesses of $1.00 \mathrm{~cm}, 1.75 \mathrm{~cm}$, and $2.00 \mathrm{~cm}$ and/or with specimen sizes of $0.5 \times 0.5 \mathrm{~cm}^{2}$, $1.0 \times 1.0 \mathrm{~cm}^{2}$, and $2.0 \times 2.0 \mathrm{~cm}^{2}$. Fig. 3, Fig. 4 , and Fig. 5 show comparatively the sound absorption curves by three different specimen size for leaf thickness $1.00 \mathrm{~cm}, 1.75 \mathrm{~cm}$, and $2.00 \mathrm{~cm}$, respectively. For instance, Fig. 3 shows the relationship between different unit size and SAC for specimens which have the same thickness but different specimen unit size for each evergreen broad-leaved tree species. In general, it is reported that the higher the density per unit volume, the higher the SACs for the same material (McGrory et al., 2012). As shown in Table 2, the SACs for each species were obtained under the similar density conditions for $D$. morbiferus within the range of $0.05-0.07\left(\mathrm{~g} / \mathrm{cm}^{3}\right)$, and for $F$. japonica within the range of $0.10-0.14\left(\mathrm{~g} / \mathrm{cm}^{3}\right)$.

In this study, the SAC showed a tendency to be higher as the thickness of the leaf layer increased under specific pressure conditions. This may be because more air gaps occur in thick leaf conditions than in thin leaf conditions under same pressure conditions. The relationship between the sample thickness and the air gap has also been considered in the results of previous studies on various materials (Hakamada et al., 2006; Taban et al., 2019; Jung et al., 2020). Under the condition of thin layer thickness, the sound absorption effect was higher as the sample size was larger, whereas under the condition of thick layer thickness, the sound absorption effect by the air gap had a greater effect than the effect of the leaf size. From these results, it is considered that the smaller the specimen size of the dry leaf under the same thickness and pressure conditions, the higher the SAC is due to the increase of the air gap. Among all the conditions of this study, the largest mean SAC was found in the condition of $0.5 \mathrm{~cm} \times 0.5 \mathrm{~cm}$ leaf size at $2.50 \mathrm{~cm}$ thickness, with 0.594 for $F$. japonica and 0.549 for $D$. morbiferus. The mean SAC of D. morbiferus in each treatment condition ranged from 0.281 to 0.549 , and 0.309 to 0.594 for $F$. japonica. These results were slightly lower than the SAC shown by undried leaves of the same tree species by Jung et al. (2020). At the level of leaf thicknesses of $1.00 \mathrm{~cm}$ and $1.75 \mathrm{~cm}$, the

Table 2. Sound absorption properties and density of evergreen broad-leaved trees

\begin{tabular}{|c|c|c|c|c|c|c|c|}
\hline \multirow{3}{*}{ Tree speices } & \multirow{3}{*}{$\begin{array}{c}\text { Leaf layer } \\
\text { thickness }(\mathrm{cm})\end{array}$} & \multicolumn{6}{|c|}{ Leaf specimen size } \\
\hline & & \multicolumn{2}{|c|}{$0.5 \times 0.5(\mathrm{~cm})$} & \multicolumn{2}{|c|}{$1.0 \times 1.0(\mathrm{~cm})$} & \multicolumn{2}{|c|}{$2.0 \times 2.0(\mathrm{~cm})$} \\
\hline & & SAC ave. & $\rho\left(\mathrm{g} / \mathrm{cm}^{3}\right)$ & SAC ave. & $\rho\left(\mathrm{g} / \mathrm{cm}^{3}\right)$ & SAC ave. & $\rho\left(\mathrm{g} / \mathrm{cm}^{3}\right)$ \\
\hline \multirow{3}{*}{ D. morbiferus } & 1.00 & $0.288 \pm 0.008 \mathrm{Bc}$ & 0.07 & $0.281 \pm 0.006 \mathrm{Bc}$ & 0.05 & $0.324 \pm 0.004 \mathrm{Ab}$ & 0.06 \\
\hline & 1.75 & $0.344 \pm 0.01 \mathrm{Cb}$ & 0.07 & $0.371 \pm 0.005 \mathrm{Bb}$ & 0.05 & $0.527 \pm 0.017 \mathrm{Aa}$ & 0.06 \\
\hline & 2.50 & $0.549 \pm 0.007 \mathrm{Aa}$ & 0.07 & $0.539 \pm 0.007 \mathrm{Aa}$ & 0.05 & $0.535 \pm 0.003 \mathrm{Aa}$ & 0.06 \\
\hline \multirow{3}{*}{ F. japonica } & 1.00 & $0.309 \pm 0.002 \mathrm{Cc}$ & 0.14 & $0.340 \pm 0.007 \mathrm{Bb}$ & 0.12 & $0.377 \pm 0.005 \mathrm{Ab}$ & 0.10 \\
\hline & 1.75 & $0.541 \pm 0.005 \mathrm{Bb}$ & 0.14 & $0.574 \pm 0.01 \mathrm{Aa}$ & 0.12 & $0.555 \pm 0.006 \mathrm{ABa}$ & 0.10 \\
\hline & 2.50 & $0.594 \pm 0.008 \mathrm{Aa}$ & 0.14 & $0.583 \pm 0.009 \mathrm{ABa}$ & 0.12 & $0.572 \pm 0.011 \mathrm{Ba}$ & 0.10 \\
\hline
\end{tabular}

SAC: Sound absorption coefficient, data are average values from 3 replications

A-C means that different capital letters in a row within each size differ significantly $(p<0.05)$

a-c means that different small letters in a column within each thickness differ significantly $(p<0.05)$ 
SAC of both species was significantly higher as the leaf specimen size increased (Table 2). These results showed a similar tendency to the sound absorption response characteristics for undried leaves of the same species by Jung et al. (2020). However, as the thickness increased, the difference in sound absorption effect according to the leaf size showed a tendency to decrease overall. In particular, in the case of D. morbi- ferus, there was no significant difference in SAC according to the difference in leaf size under the condition of $2.5 \mathrm{~cm}$ thickness $(p<0.05)$. In the case of $F$. japonica, the difference in sound absorption effect ( 0.022$)$ between the leaf sizes of $0.5 \times 0.5 \mathrm{~cm}^{2}$ and $2.0 \times 2.0 \mathrm{~cm}^{2}$ under the condition of $2.50 \mathrm{~cm}$ thickness was relatively weak compared to the case of $1.00 \mathrm{~cm}$ thickness (0.068). Under the condition of $1.00 \mathrm{~cm}$

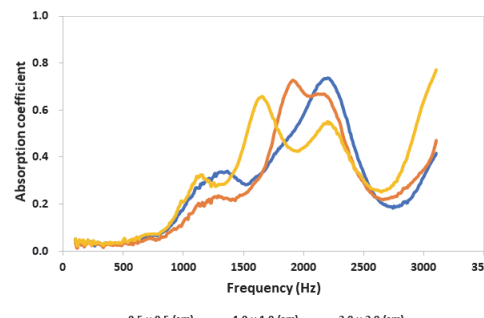

(a) D. morbiferus

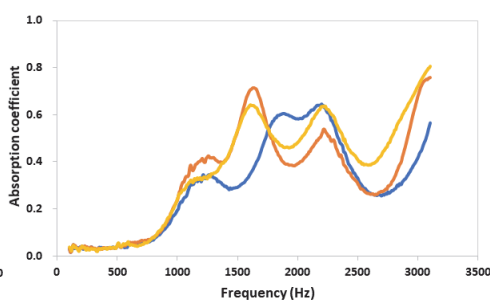

(b) F. japonica

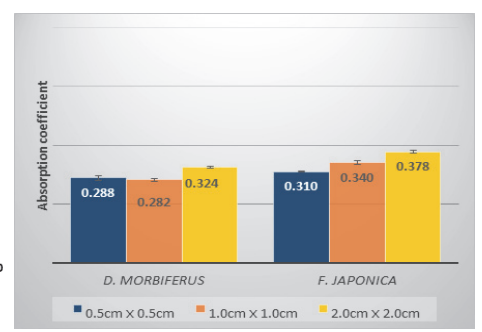

(c) Average of SAC

Fig. 3. Comparison of sound absorption capacity between three size types of air-dried leaves with $1.00 \mathrm{~cm}$ thickness.

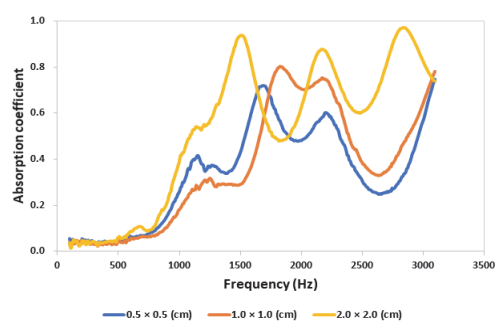

(a) D. morbiferus

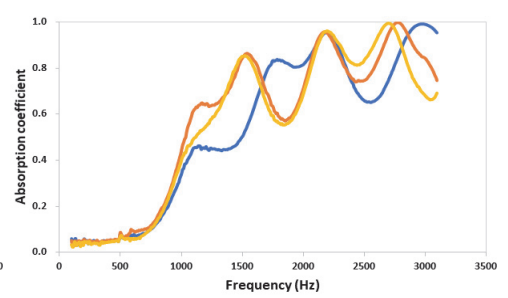

(b) F. japonica

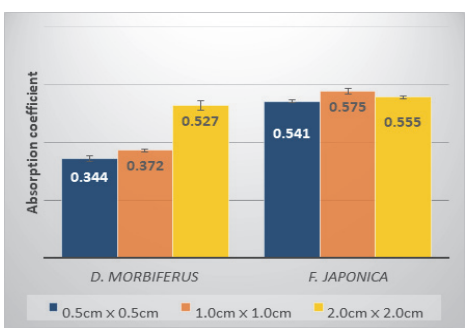

(c) Average of SAC

Fig. 4. Comparison of sound absorption capacity between three size types of air-dried leaves with $1.75 \mathrm{~cm}$ thickness.

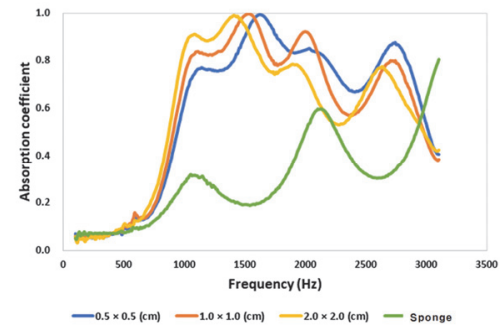

(a) D. morbiferus

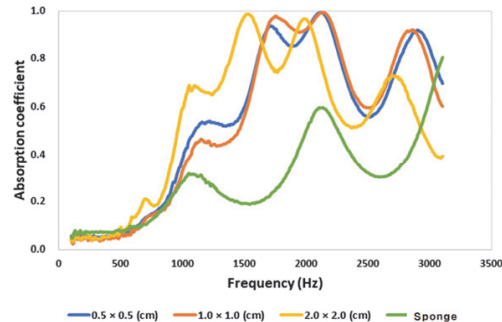

(b) F. japonica

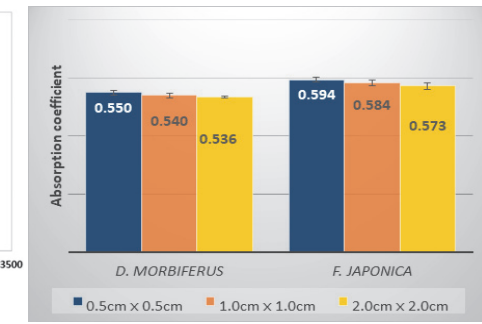

(c) Average of SAC

Fig. 5. Comparison of sound absorption capacity between three size types of air-dried leaves with $2.50 \mathrm{~cm}$ thickness. 
thickness filled with a leaf size of $0.5 \times 0.5 \mathrm{~cm}^{2}$, the sound absorption coefficient was relatively lower than that of the other two thickness conditions, and in particular, in the case of D. morbiferus, the sound absorption coefficient was lower than that of sponge 0.303 (Table 2). Under the condition of the leaf layer thickness of $1 \mathrm{~cm}$, the SAC was very low at less than 0.1 in the frequency range below $1,000 \mathrm{~Hz}$, and the maximum SAC thereafter was less than 0.7 as shown in Fig. 3. These results showed a distinct difference from the steep rise of the sound absorption coefficient from 0.8 to 1.0 in the frequency range above approximately $1,000 \mathrm{~Hz}$ in the case of the leaf thicknesses of 1.75 cm (Fig. 4) and $2.50 \mathrm{~cm}$ (Fig. 5).

Therefore, the sound absorption effect of each leaf size in the $1.75 \mathrm{~cm}$ and $2.50 \mathrm{~cm}$ thick conditions, excluding the $1.00 \mathrm{~cm}$ thick condition, was compared and analyzed intensively for each frequency band, and the results are as follows.

\subsection{Sound absorption properties by frequency band}

The overall mean SAC was higher as the size of the leaf specimen increased under the thin leaf layer of $1.00 \mathrm{~cm}$, whereas the significant difference in SAC by the leaf specimen size tended to decrease under the thick leaf layer of $1.75 \mathrm{~cm}$ and $2.00 \mathrm{~cm}$. Fig. 4(a) (b) show the SAC response curves for each specimen size in the $1.75 \mathrm{~cm}$ thickness of the air-dried leaves according to the frequency band. Under the condition of 1.75 $\mathrm{cm}$ thickness, the mean SAC was relatively higher in $F$. japonica species than in D. morbiferus species as shown in Fig. 4(c). In particular, these results showed that the sound absorption effect was higher in all leaf size conditions regardless of the leaf size.

The sound absorption coefficient of both species increased rapidly at $500 \mathrm{~Hz}$, but the sound absorption effect of $D$. morbiferus species in the subsequent fre- quency band was significantly lower than that of $F$. japonica species. These results are in contrast to the fact that the SAC of $F$. japonica species is continuously and gradually increasing from $1,000 \mathrm{~Hz}$ to 3,000 Hz.

From the above results, obviously, the difference in sound absorption coefficient according to the increase in frequency was more sensitive and consistent in the $F$. japonica than in the D. morbiferus, and the SAC tended to increase as the frequency increased in the $F$. japonica. This difference in sound absorption characteristics is thought to be due to the difference in the fundamental structural characteristics of the fresh leaf between these two tree species, and these characteristics are considered to have secondly influenced the difference in pore composition, resonant characteristics, etc. of the air-dried leaves in specimen composition. In previous studies (Kang and Park, 2001; Koizumi et al., 2002; Hakamada et al., 2006; Ismail et al., 2010; Taban et al., 2019), it was reported that the porosity of the same absorption material under the same pressure condition is a factor that has a major influence on the sound absorption characteristics according to the frequency band. In a study on the effect of fiber type, fiber size, material thickness, density, airflow resistance and porosity on SAC (Hoda, 2009), it was reported that air gap is involved in further increasing the SAC value in mid and higher frequencies. Under the condition of $1.75 \mathrm{~cm}$ in leaf thickness of D. morbiferus, only $2.0 \times 2.0 \mathrm{~cm}^{2}$ in leaf size showed a high SAC of 0.5 or more (Table 2). It can be seen that these results originate from the difference in three frequency range of $1,500 \mathrm{~Hz}, 2300 \mathrm{~Hz}$, and $3,800 \mathrm{~Hz}$ as shown in Fig. 5(a).

The highest SAC of D. morbiferus under the 2.5 $\mathrm{cm}$ leaf thickness condition was found in the frequency range of $1,500 \mathrm{~Hz}$ to $2,300 \mathrm{~Hz}$ without any significant difference in all leaf sizes as shown in Table 2 and Fig. 5(a). The highest SAC of F. japonica 
was found at $1,600 \mathrm{~Hz}$ for both leaf sizes of $0.5 \times$ $0.5 \mathrm{~cm}^{2}$ and $1.0 \times 1.0 \mathrm{~cm}^{2}$ as shown in Fig 5(b).

One singularity here is that in the frequency below approximately $1,500 \mathrm{~Hz}$, the larger the leaf size, the higher the coefficient, but above approximately 1,500 $\mathrm{Hz}$, the smaller the leaf, the higher the coefficient.

From the above study results, it was found that the sound-absorbing effect was generally high in the conditions of $1.75 \mathrm{~cm}$ or more in air-dried leaf layer thickness of the two evergreen broad-leaved tree species, and it was also found that the effect was much higher in the frequency range above approximately $1,000 \mathrm{~Hz}$. Therefore, the results on the sound absorption effect of the air-dried leaves obtained in this study were more practical than the results of the fresh leaf for the same tree species. The results of this study are meaningful in providing basic data for the manufacture of eco-friendly sound-absorbing materials using air-dried leaf materials of the evergreen broad-leaved tree species into molded products.

\section{CONCLUSION}

The sound absorption coefficient of air-dried leaves for Dendropanax morbiferus and Fatsia japonica as evergreen broad-leaved tree species was estimated and compared; the air-dried leaf layer thicknesses of 1.00 $\mathrm{cm}, 1.75 \mathrm{~cm}$, and $2.50 \mathrm{~cm}$ and the leaf sizes of 0.5 $\times 0.5 \mathrm{~cm}^{2}, 1.0 \times 1.0 \mathrm{~cm}^{2}$, and $2.0 \times 2.0 \mathrm{~cm}^{2}$. The measured values of sound absorption capacity for all conditions were statistically analyzed by Duncan's multiple range test. The results are summarized as follows:

(1) In both species, the sound-absorbing capacity of air-dried leaves was lower than that of undried leaves. At the level of leaf thicknesses of 1.00 $\mathrm{cm}$ and $1.75 \mathrm{~cm}$, the SAC of both species was significantly higher as the leaf specimen size increased. These results showed a similar ten- dency to the sound absorption response characteristics for undried leaves of the same species.

(2) However, as the thickness increased, the difference in sound absorption effect according to the leaf size showed a tendency to decrease overall. In particular, in the case of D. morbiferus, there was no significant difference in SAC according to the difference in leaf size under the condition of $2.5 \mathrm{~cm}$.

(3) The highest SAC of D. morbiferus under the $2.5 \mathrm{~cm}$ leaf thickness condition was found in the frequency range of $1,500 \mathrm{~Hz}$ to $2,300 \mathrm{~Hz}$ without any significant difference in all leaf sizes. The highest SAC of $F$. japonica was found at $1,600 \mathrm{~Hz}$ for both leaf sizes of $0.5 \times$ $0.5 \mathrm{~cm}^{2}$ and $1.0 \times 1.0 \mathrm{~cm}^{2}$.

\section{REFERENCES}

ASTM C 384-04. 2016. Standard Test Method for Impedance and Absorption of Acoustical Materials by Impedance Tube Method. American Society for Testing and Materials, Philadelphia, PA, USA.

Bujoreanu, C., Nedeff, F., Benchea, M., Agop, M. 2017. Experimental and theoretical considerations on sound absorption performance of waste materials including the effect of backing plates. Applied Acoustics 119: 88-93.

Byeon, H.S., Park, J.H., Hwang, K.K., Park, H.M., Park, B.S., Chong, S.H. 2010. Sound absorption property of heat-treated wood at a low temperature and vacuum conditions. Journal of the Korean Wood Science and Technology 38(2): 101-107.

Ersoy, S., Küçük, H. 2009. Investigation of industrial tea-leaf-fibre waste material for its sound absorption properties. Applied Acoustics 70(1): 215-220.

Hwang, K.H., Kim, G.H., Park, B.S., Park, J.H., Byeon, H.S., Lee, W.H. 2008. Sound absorption characteristic of resonator by hole position and wood species. 
Journal of the Korean Wood Science and Technology 36(3): 9-16.

Hakamada, M., Kuromura, T., Chen, Y., Kusuda, H., Mabuchi, M. 2006. Sound absorption characteristics of porous aluminum fabricated by spacer method. Journal of Applied Physics 100: 114908. https://doi.org/10.1063/1.2390543

Hoda, S.S. 2009. Factors influencing acoustic performance of sound absorptive materials. Australian Journal of Basic and Applied Sciences 3(4): 4610-4617.

Ismail, L., Ghazali, M.I., Mahzan, S., Zaidi, A.A. 2010. Sound absorption of Arenga Pinnata natural fiber. World Academy of Science, Engineering and Technology 67: 804-806.

Iswanto, A.H., Hakim, A.R., Azhar, I., Wirjosentono, B., Prabuningrum, D.S. 2020. The physical, mechanical, and sound absorption properties of sandwich particleboard ( $\mathrm{SPb})$. Journal of the Korean Wood Science and Technology 48(1): 32-49.

Jang, E.S., Kang, C.W., Kang, H.Y., Jang, S.S. 2018. Sound absorption propery of traditional Korean natural wallpaper (Hanji). Journal of the Korean Wood Science and Technology 46(4): 703-712. Jung, S.Y., Yeom, D.H., Kong, R.K., Shin, G.G., Lee, K.S., Byeon, H.S. 2020. Sound absorption property of the leaves of two evergreen broad-leaved tree species, Dendropanax morbiferus and Fatsia japonica. Journal of the Korean Wood Science and Technology 48(5): 631-640.

Kang, C.W., Park, H.J. 2001. Improvement of sound absorption capability of wood and wood-based board by resonant absorption. Journal of the Korean Wood Science and Technology 29(1): 16-21.

Kang, C.W., Lee, N.H. 2005. Changes of sound absorption capability and anatomical features of wood by delignification treatment. Journal of the Korean Wood Science and Technology 33(4): 9-14.

Kang, C.W., Kang, U, Jung, I.S., Park, H.J., Jeon. S.S. 2008. Sound absorption capability and anatomical features of Oak Mushroom Bed Log. Journal of the Korean Wood Science and Technology 36(1): 54-60.

Kang, C.W., Kang, H.Y. 2015. Effect of flame resistant treatment on the sound absorption capability of sawdust-mandarin peel composite particleboard. Journal of the Korean Wood Science and Technology 43(4): 511-517.

Kang, C.W., Lee, N.H., Jang, S.S., Kang, H.Y. 2019a. Sound absorption coefficient and sound transmission loss of rice hull mat. Journal of the Korean Wood Science and Technology 47(3): 290-298.

Kang, C.W., Jang, E.S., Jang, S.S., Kang, H.Y., Kang, S.G., Oh, S.C. 2019b. Sound absorption rate and sound transmission loss of wood bark particle. Journal of the Korean Wood Science and Technology 47(4): 425-441.

Kang, C.W., Jang, E.S., Jang, S.S., Cho, J.I., Kim, N.H. 2019c. Effect of heat treatment on the gas permeability, sound absorption coefficient, and sound transmission loss of Paulownia tomentosa wood. Journal of the Korean Wood Science and Technology 47(5): 644-654.

Koizumi, T., Tsujiuchi, N., Adachi, A. 2002. The development of sound absorbing materials using natural bamboo fibers. WIT Transactions on The Built Environment, 59.

Korea Forest Service (KFS). 2002. Restoration and development for bio-technology in warm temperate forest; Industry, academy and government cooperative study IV. Korea. Korea Forest Service, Korea, pp. 58.

Korea Forest Service (KFS). 2018. Annual action plan of forest resources. Korea Forest Service, Korea, pp. 338.

Lee, J.M. 2001. A study on the acoustic absorbent characteristics of recycled materials. Master Thesis, Sun Moon University, Korea.

McGrory, M., Cirac, D.C., Gaussen, O., Cabrera, D. 2012. Sound absorption coefficient measurement: 
Re-examining the relationship between impedance tube and reverberant room methods. Proceeding of Acoustics 2012, Fremantle, Australia. Australian Acoustical Society, 1-8.

Nor, M.J.M., Jamaludin, N., Tamiri, F.M. 2004. A preliminary study of sound absorption using multi-layer coconut coir fibers. Electronic Journal Technical Acoustics 3: 1-8.

Oldham, D.J., Egan, C.A., Cookson, R.D. 2011. Sustainable acoustic absorbers form the biomass. Applied Acoustics 72(6): 350-363.

Taban E., Khavanin, A., Jafari, A.J., Faridan, M.,
Tabrizi, A.K. 2019. Experimental and mathematical survey of sound absorption performance of data palm fibers. Heliyon 5(6): 1-8.

Vashum K.T. 2012. Methods to estimate above-ground biomass and carbon stock in natural forests: A review. Journal of Ecosystem \& Ecography 2(4): 1-7.

Won, K.R., Hong, N.E., Kang, S.U., Park, S.B., Byeon, H.S. 2015. Sound absorption property of carbonized medium density fiberboards at different carbonizing temperatures. Journal of the Korean Wood Science and Technology 43(2): 206-213. 